University of Wollongong

Research Online

Faculty of Social Sciences - Papers (Archive) Faculty of Arts, Social Sciences \& Humanities

$1-1-2019$

Exploring the Relationships Between Eating Disorders and Mental Health in Women Attending Residential Substance Use Treatment

Laura Robinson

University of Wollongong, laurar@uow.edu.au

Peter James Kelly

University of Wollongong, pkelly@uow.edu.au

Frank P. Deane

University of Wollongong, fdeane@uow.edu.au

Samantha L. Reis

University of Wollongong, sreis@uow.edu.au

Follow this and additional works at: https://ro.uow.edu.au/sspapers

Part of the Education Commons, and the Social and Behavioral Sciences Commons

Research Online is the open access institutional repository for the University of Wollongong. For further information contact the UOW Library: research-pubs@uow.edu.au 


\title{
Exploring the Relationships Between Eating Disorders and Mental Health in Women Attending Residential Substance Use Treatment
}

\begin{abstract}
Objective: Comorbid eating disorders (EDs) and ED symptoms are highly prevalent among women with substance use disorders and may be a barrier to recovery. Higher rates of psychiatric illness are common when more than one disorder is present. Yet little is known about the rates and risk factors for EDs/ED symptoms in women attending treatment centers in Australia. The primary aim is to examine the prevalence of ED symptoms among women attending treatment centers. This study also examines past physical and sexual abuse and mental health as specific predictors of EDs/ED symptoms.

Methods: Participants were 1,444 women attending residential treatment for substance use issues provided by the Salvation Army in Australia. Measures included the Addiction Severity Index, the Eating Disorder Screen for Primary Care, medication use, hospitalization, mental health, and past abuse.

Results: Alcohol was the primary substance of concern for $53.3 \%$ of the women, followed by amphetamines $(17.5 \%)$, and the mean age was 37.83 years $(S D=10.8)$. Nearly $60 \%$ of women screened positive for ED symptoms and 32\% reported a previous or current ED. Women with a history of sexual abuse had significantly greater odds (1.96) of positive screening for an ED compared to those without a history of sexual abuse. Similarly, compared to women without a history of physical abuse, those who did have a history had significantly higher odds (1.59) of a positive screen for an ED. These women were also significantly more likely to have had a health care provider recommend they take medications for psychological or emotional problems in the past 30 days, $\chi 2(1)=8.42, p=.004$, and during their lifetime, $\chi 2(1)=17.89, p<.001$. They also had a significantly greater number of overnight hospitalizations for medical problems compared to those who screened negative, $t(137)=-2.19, p=.03$.
\end{abstract}

Conclusions: Women with comorbid substance use issues and EDs are highly likely to have a history of past abuse. This combination of comorbidities makes treatment and recovery difficult. Increased awareness and research are required to explore integrated approaches to treatment that accommodate these vulnerabilities and improve long-term outcomes.

\section{Disciplines}

Education | Social and Behavioral Sciences

\section{Publication Details}

Robinson, L. D., Kelly, P. J., Deane, F. P. \& Reis, S. L. (2019). Exploring the Relationships Between Eating Disorders and Mental Health in Women Attending Residential Substance Use Treatment. Journal Of Dual Diagnosis, Online First 1-11. 


\section{Exploring the relationships between eating disorders and mental health in women attending residential substance use treatment}

Laura D. Robinson, PhD, Career Development Fellow ${ }^{1,2}$, Peter J. Kelly, PhD, Associate Professor ${ }^{1,2}$, Frank P. Deane, PhD, Professor ${ }^{1,2}$, Samantha L, Reis, PhD, Career Development Fellow ${ }^{1}$

${ }^{1}$ School of Psychology, University of Wollongong, Australia

${ }^{2}$ Illawarra Institute for Mental Health, School of Psychology, University of Wollongong, Australia.

Author for correspondence: Laura D Robinson, School of Psychology, University of Wollongong, Wollongong, NSW, Australia, 2522. Telephone: 024221 5035, Email: 1aurar@uow.edu.au

\section{Acknowledgements}

A/Prof Kelly holds research consultancies with The Salvation Army and conducts ongoing collaborative research with The Salvation Army. 
Objectives: Comorbid eating disorders (ED) and eating disorder symptoms are highly prevalent among women with substance use disorders and may be a barrier to recovery. Higher rates of psychiatric illness are common when more than one disorder is present. Yet, little is known about the rates and risk-factors for eating disorders/eating disorder symptoms in women attending treatment centres in Australia. The primary aim is to examine the prevalence of eating disorder symptoms among women attending treatment centres. This study also examines past physical and sexual abuse, and mental health as specific predictors of eating disorders/eating disorder symptoms.

Methods: Participants were 1444 women attending residential treatment for substance use issues provided by the Salvation Army in Australia. Measures included the Addiction Severity Index (ASI), the Eating Disorder Screen for Primary Care (ESP), medication use, hospitalisation, mental health, and past abuse.

Results: Alcohol was the primary substance of concern for $53.3 \%$, followed by amphetamines $(17.5 \%)$ and the mean age was 37.83 years $(S D=10.8)$. Nearly $60 \%$ of women screened positive for ED symptoms and 32\% reported a previous or current eating disorder. Women with a history of sexual abuse had significantly greater odds (1.96) of positive screening for an eating disorder compared to those without a history of sexual abuse Similarly, compared to women without a history of physical abuse, those who did have a history had significantly higher odds (1.59) of a positive screen for an eating disorder. These women were also significantly more likely to have had a health care provider recommend they take medications for psychological or emotional problems in the past 30 days $\left(\chi^{2}(1)=8.42, p=.004\right)$, and during their lifetime $\left(\chi^{2}(1)=\right.$ $17.89, p<.001)$. They also had a significantly greater number of overnight hospitalisations for medical problems compared to those who screened negative $(t(137)=-2.19, p=.03)$.

Conclusions: Women with comorbid substance use issues and eating disorders are highly likely to have a history of past abuse. This combination of comorbidities makes treatment and recovery difficult. Increased awareness and research are required to explore integrated approaches to treatment that accommodate these vulnerabilities and improve long-term outcomes. 
Keywords: substance use, eating disorder symptoms, co-occurring disorders, treatment

\section{INTRODUCTION}

One of the greatest challenges in treating substance use disorders (SUD) is high comorbidity (Davidson \& White, 2007). Co-occurring substance use and mental health disorders have been identified in $56 \%$ of individuals attending detoxification facilities (Vella, Deane, \& Kelly, 2015). Comorbidity between SUDs and other mental disorders are a major cause of disability and creates a significant financial burden (NSW Health, 2015). Comorbidity is common, with an estimated 25 to $50 \%$ of those with a SUD reporting another mental disorder (Teeson, Slade, \& Mills, 2009). Comorbidity is associated with greater severity of illness, poorer outcomes from treatment, and higher mortality rates (Harrop \& Marlatt, 2010; Teeson et al., 2014).

Epidemiological data suggest that women with SUDs report eating disorders or eating disorder behaviours at rates around 11 times that of the general population (CASA, 2003). More recently, research suggests that individuals with SUD are more likely to binge eat and have subthreshold eating disorders than those without SUD (Brewerton, 2011; Calero-Elvira et al., 2009). Further, women experiencing both SUD and eating disorders have lower abstinence rates in comparison to women without eating disorder symptoms (Cohen, et al., 2010). It is possible that, once established, these comorbid conditions mutually influence one another such that symptoms of one disorder serve to perpetuate and/or intensify symptoms of the other (Teeson et al., 2014), presenting challenges to treatment. For example, alcohol use may trigger binge eating for individuals with bulimia nervosa (BN) (Gadalla \& Piran, 2007).

Recent research shows that the prevalence of obesity is lower in drugdependent individuals using opioids or stimulants only when compared to the general population (Hu et al., 2018). This differential has been attributed to the weight-loss effects of these drugs. However, there are reports that recovery from stimulant use is commonly accompanied by weight gain because the weight-loss effects of the substance use are no longer at work (Brecht, O’Brien, von Mayrhauser, \& Anglin, 2004). This may trigger eating disorder behaviours in an attempt to avoid weight gain. 
Indeed, a recent study of American women in substance abuse treatment reported that $71 \%$ were concerned about weight gain during recovery (Warren, Lindsay, White, Claudat, \& Velasquez, 2013). Rates of BN within SUD populations were estimated to be as high as $41 \%$, compared to $10 \%$ for AN (Gadalla \& Piran, 2007). These results suggest a strong need to assess, screen for, and treat bulimic behaviours within SUDs populations (Gadalla \& Piran, 2007).

The comorbidity of eating disorders and SUDs is not surprising given the shared risk factors for both eating disorders and substance abuse disorders including brain chemistry (e.g., disturbances in dopaminergic and serotonin systems), familial heritability factors, emotional dysregulation (e.g., inability to manage negative affect, decreased emotional awareness, intense expression or experience of emotion, emotional rigidity and cognitive reappraisal difficulties), low self-esteem and anxiety (CASA, 2003; Harrop \& Marlatt, 2010; Schulte, Grilo, \& Gearhardt, 2016) . Both disorders share common characteristics including craving, compulsive behaviour, secrecy, and social isolation (CASA, 2003). Personality traits like impulsivity have also been highlighted as relevant to the development and prognosis of both eating disorders and SUDs (Dawe \& Loxton, 2004; Schulte et al., 2016). Thus, there may be a number of underlying and intertwined mechanisms by which SUDs and eating disorders manifest and predict poorer outcomes for the individual in therapeutic settings (Schulte et al., 2016).

Past trauma may be one mechanism by which shared susceptibility to SUDs and EDs occurs. There is a well-established link between trauma, such as sexual or physical abuse (Cohen et al., 2010), and SUDs. For example, a German study found self-reported sexual abuse rates of $66 \%$ and $35 \%$ among women diagnosed with opioid dependence and alcohol dependence respectively (Schäfer et al., 2014; Schäfer et al., 2009). Substance use is commonly used as a maladaptive approach to coping with past traumas (Ullman, Relyea, Peter-Hagene, \& Vasquez, 2013). Further, compared to women with no abuse, those who report childhood physical abuse have up to twice the odds of exhibiting eating disorders symptoms (Rayworth, Wise, \& Harlow, 2004), and to have profound effects on body image issues that contribute to eating disorder symptoms (Treuer, Koperdák, Rózsa, \& Füredi, 2005). Unusually high rates of lifetime sexual and physical abuse have been reported in women with comorbid EDs and substance use issues (Dworkin, 2018; Dworkin, Menon, Bystrynski, \& Allen, 2017; Gilchrist, Gruer, \& Atkinson, 2007). An addiction model that provides a 
framework for understanding how trauma increases the risk of SUDs is the 'selfmedication' hypothesis (Khantzian, 1997). According to this hypothesis, individuals use substances following trauma as a means to managing or avoiding distressing symptoms and painful emotions (Hien, Cohen, \& Campbell, 2005; Roberts, Roberts, Jones, \& Bisson, 2015). This hypothesis has been supported by large scale research linking childhood sexual abuse, interpersonal trauma, and PTSD symptoms to substance use coping for women (Ullman et al., 2013). Other evidence links a history of sexual assault with increased alcohol use. Women with a history of sexual assault who drink alcohol to cope and reduce tension are at increased risk of developing drinking problems than those with no history of sexual assault (Ullman, Filipas, Townsend, \& Starzynksi, 2005). Further, research from a sample of men and women with comorbid PTSD and alcohol use disorder found that PTSD symptom severity preceded increases in subsequent alcohol consumption the same day and the following day, with drinking motives moderating this link (Simpson, Stappenbeck, Luterek, Lehavot, \& Kaysen, 2014). This provides support for the idea that alcohol consumption may be motivated by a need to alleviate distressing symptoms associated with past trauma. The self-medication hypothesis also provides a framework for understanding the relationship between trauma and eating disorders. For instance, the hypothesis states that, in a similar way to SUDs, binge eating and other eating disorder symptoms are used as a means for coping with the adverse emotional physical effects following trauma (Brewerton, 2011; Holzer, Uppala, Wonderlich, Crosby, \& Simonich, 2008; Schoemaker, Smit, Bijl, \& Vollebergh, 2002). Past psychological abuse has been reported as a specific risk factor for bulimia in a population-based study (Schoemaker et al., 2002), with binging and purging used as a maladaptive coping mechanism. Women who experience both SUD and eating disorders often report high rates of abuse (Harrop \& Marlatt, 2010), and the selfmedication hypothesis is one explanation for their similar aetiology.

Other models may also explain links between SUD, eating disorders and past trauma. For example, the mutual maintenance model proposes that SUD and trauma cyclically sustain each other, with trauma symptoms leading to increases in compensatory substance use, and substance use subsequently either maintaining or amplifying the trauma symptoms (Kaysen et al., 2011; Kaysen et al., 2006; Simpson et al., 2014). Alternatively, shared genetic relationships or common personality factors - such as impulsivity - may explain comorbidity between trauma, SUD and 
eating disorders, particularly those featuring binge eating (Corstorphine, Waller, Lawson, \& Ganis, 2007; Dawe \& Loxton, 2004; Mole et al., 2015).

Of great concern is the elevated risk of psychological disorders and mortality associated with both eating disorder symptoms and SUD (Franko et al., 2005; Harrop \& Marlatt, 2010). Worse still are the mental health outcomes when experiencing both disorders concurrently. For instance, Bonfa et al., (2008) report that among drugaddicted females there were higher rates of psychopathological distress in those with eating disorder symptoms than in those without these symptoms. Similarly, Bulik et al. (2004) found greater depressive and anxiety symptoms in women with comorbid eating disorders and alcohol use disorders compared to women without these disorders. In addition, women with SUDs who engaged in binge eating reported higher depressive symptoms than those who did not (Cohen et al., 2010). Another critical concern is that treatment is difficult when comorbidity is present, and the relapse risk is high for both disorders (CASA, 2003). For example, Cohen et al. (2010) examined data from a sample of American women with co-occurring PTSD and SUDs attending an outpatient substance use program. Results indicated that nearly $30 \%$ reported engaging in binge eating, and these women demonstrated decreased abstinence rates compared to those who did not. Evidence also suggests that successful treatment of one may result in an increase in symptoms in the other disorder (CASA, 2003). The impact of comorbidity on treatment outcome and symptom severity highlights the need to broaden our understanding of this highly vulnerable group of women. Despite the higher susceptibility to psychological disorders and treatment relapse when both disorders are present, assessing and treating eating disorder symptoms in residential treatment settings remains fairly uncommon. As such, researchers have recommended more research into the correlates of weight-related concerns in residents such the type of drug used, age, addiction severity and psychiatric comorbidity (Killeen, Brewerton, Campbell, Cohen, \& Hien, 2015; Warren et al., 2013).

International research demonstrates high prevalence of eating disorders and subthreshold eating disorder behaviours in SUD treatment populations, but few studies have investigated comorbidity and outcome in the Australian context. The present study explores, for the first time, eating disorder symptoms in women attending Australian residential centres for substance use issues. Further, this study examines known risk factors and correlates, such as past physical and sexual abuse, 
and mental health, for eating disorder symptoms to better understand these variables among women with substance use issues in treatment. Hospitalisation and recent medication intake are also examined.

\section{METHODS}

\section{Participants and Procedure}

Data were collected as part of a project regularly evaluating the effectiveness of The Salvation Army Recovery Service Centres situated in nine locations in New South Wales, Australian Capital Territory and Queensland, Australia. Clients can attend residential treatment for up to ten months. The programs operate as therapeutic communities and provide a range of activities designed to improve social, psychological, occupational and interpersonal functioning. As well as offering individual case planning, there are 12-step and other groups, education and training programs. Measures are administered to participants by staff as part of the intake process within 7 days of admission. All participants were provided with written participant information forms and have the opportunity to discuss potential participation with both researchers and facility staff. Consent was provided by completing and returning the survey following the presentation. Approval from the University of Wollongong's Human Research Ethics Committee. Centres provide residential alcohol and other substance abuse treatment for men and women. Given the much higher rates of ED found in women compared to men, the present study included only females. Females comprise approximately $20 \%$ of total admissions to these services. Data were collected for the period 2008 to 2017 . In the current study the final sample comprised 1444 women with an average age of 37.83 years ( $S D$ $=10.89$, range 18.15 to 74.38 years). Average age of onset of alcohol or other drug use was 15.82 years $(S D=6.98)$. The most frequent primary drug of concern was alcohol (53\%). Other sociodemographic and clinical characteristics are provided in Table 1.

\section{Measures}

Depression Anxiety Stress Scale (DASS). This 21-item self-report questionnaire yields three subscales: depression, anxiety, and stress (Lovibond \& Lovibond, 1995). Each subscale has 7-items coded on a 4-point severity/frequency scale to indicate to the extent to which each of the three states had been experienced during the past week. An example depression item is, "I felt that I had nothing to look forward to"; 
and anxiety item, "I found it hard to wind down", and stress item, "I found myself getting agitated". Cronbach's alpha for the current study for depression (Cronbach's $\alpha=.89$ ), anxiety (Cronbach's $\alpha=.76$ ) and stress (Cronbach's $\alpha=.81$ ) were considered adequate.

Eating disorder screen (ESP). Eating Disorder Screen for Primary Care (ESP) was used to detect eating disorders (Cotton, Ball, \& Robinson, 2003). The ESP is comprised of four items all with a yes or no response format. Having two or more positive responses indicates a positive screen result. The ESP is a brief instrument designed to identify individuals with any type of eating disorder (Cotton, Ball \& Robinson, 2003). The four items were: “Are you satisfied with your eating patterns?”; "Do you ever eat in secret?"; "Does your weight affect the way you feel about yourself?"; and "Do you suffer or have you ever suffered in the past from an eating disorder?". A "no" response to the first question and a "yes" to the remaining questions were classified as positive scores (or abnormal response). The Cronbach's alpha for the present study was .69, similar to that of Heiland, Murray and Edley's (2009) ( $\alpha=$.74). Individual items have been used in previous research with high sensitivity and specificity in samples of college students and women exposed to intimate partner violence in a primary care setting (Anstine \& Grinenko, 2000; Freund, Graham, Lesky, \& Moskowitz, 1993). In the present study, both an overall screen result and individual items are used.

Eating disorder symptoms. The following question from the Mental Health Screening Form-III (MHSF-III; Carroll \& McGinley, 2001) was used, "Was there ever a period in your life when you spent a lot of time thinking and worrying about gaining weight, becoming fat, or controlling your eating? For example, by repeatedly dieting or fasting, engaging in much exercise to compensate for binge eating, taking enemas, or forcing yourself to throw up?". It required a yes or no response. The MHSF-III was designed for use in the substance use population as a screening tool to identify cooccurring psychiatric issues, and the ED screening item has been found to have strong content and construct validity (see Carroll \& McGinley, 2001).

Addiction Severity Index (ASI). The ASI is a semi-structured interview used to assess several domains: drug, alcohol, medical, family, psychiatric, employment and legal (McLellan et al., 1992). It is one of the most widely used substance abuse assessment 
tools (Bodin \& Romelsjö, 2006). In the present study, the questions on drug, alcohol, medical, psychiatric, and family/social relationships were included in the analysis.

Family/social relationships. Two items from this section were used: Has anyone ever abused you physically in your life? Has anyone ever abused you sexually in your life?. Responses were yes/no.

Psychiatric Status. One item was included with respondents asked to specify 'yes' or 'no' for the past 30 days and for their lifetime. The item was, Has a health care provider recommended you take any medications for psychological or emotional problems?.

\section{Data analysis}

Data were analysed using SPSS (Corp, 2016, version 24). Demographic variables, primary drug of use, and eating disorder symptoms were described using frequencies. Binary regression analysis was used to examine predictors of a positive score on the eating disorders screen, past diagnosis of an eating disorder, and eating disorder behaviours. Eating disorders are much more prevalent in younger women, so age was used as a covariate in the analyses (Stice, Marti, \& Rohde, 2013). Hospitalisations were analysed using $t$-tests, and medication use with chi-square.

\section{RESULTS}

Sociodemographic and clinical characteristics are shown in Table 1. The majority of the sample had a high school level education (81.2\%), $41 \%$ had spent the most of the past three years in some form of paid employment, $60 \%$ had never married, and another $34 \%$ were separated, divorced or widowed.

Nearly $60 \%$ of individuals were positive on the eating disorder screen (Table 1). Examining the items of the eating disorder screening tool showed that weight affected the way individuals felt about themselves in nearly $38.2 \%$ of clients, and another $31.6 \%$ reported they previously had or currently have an eating disorder. Slightly fewer reported being dissatisfied with eating patterns or eating in secret $(26.0 \%$ and $14.9 \%$ respectively).

$$
<\text { Insert Table } 1 \text { here> }
$$

Individuals with a history of sexual abuse had significantly higher odds (1.96) of positive screening for an eating disorder compared to those without a history of sexual 
abuse. Further, those with a history of sexual abuse had significantly higher odds (1.93) of reporting eating symptoms as measured by the MHSF. Compared to individuals without a history of physical abuse, those who did have a history had significantly higher odds (1.59) of a positive screen for an eating disorder and significantly higher odds (1.93) of exhibiting eating disorder symptoms (as per the MHSF) (Table 2). Individuals reporting alcohol as the primary substance had significantly higher odds (1.49) of having eating disorder symptoms than those reporting other drugs as the primary substance (as per the MSHF). This was not the case onthe eating disorder screen.

$<$ Insert Table 2 here $>$

In relation to the individual items of the eating disorder screen, after adjusting for age, compared to those without a history of sexual abuse, those with a history had significantly greater odds (1.71) of reporting that their weight affected the way they feel about themselves; 1.72 greater odds of reporting a current or past eating disorder; and 1.75 odds of reporting eating in secret (Table 3 ). Individuals with a history of physical abuse, compared to those without, had significantly higher odds (1.44) of reporting that their weight affected the way they feel about themselves; 1.36 greater odds of a current and/or past eating disorder; and 1.75 great odds of eating in secret. Individuals reporting alcohol as the primary substance had significantly higher odds (1.36) of having a past or current eating disorder than those reporting other drugs as the primary substance.

$<$ Insert Table 3 here $>$

Those who had a positive eating disorder screen reported significantly greater numbers of overnight hospitalisations for medical problems compared to those who were negative $(t(137)=-2.19, p=.03)$. Additionally, those who screened positive were significantly more likely to have had a health care provider recommend they take medications for psychological or emotional problems in the past 30 days $\left(\chi^{2}(1)=\right.$ $8.42, p=.004)$, and during their lifetime $\left(\chi^{2}(1)=17.89, p<.001\right)$.

\section{DISCUSSION}

This paper aimed to explore risk factors and correlates, including prior sexual or physical abuse, primary drug of abuse, and mental health, for eating disorder symptoms among women in Australian residential substance abuse treatment centres. Nearly $60 \%$ reported at least two of the four eating disorder symptoms, which 
indicates a positive screen for an eating disorder, and 32\% of women reported that they currently have, or previously had an eating disorder. This appears to be at the high end of the range of other observations where eating disorders or symptoms of eating pathology have been reported in $20 \%$ to $30 \%$ of female substance abusers (Bonfa et al., 2008; CASA, 2003). This could be because women who attend residential substance use treatment generally have the most severe substance use issues (Sacks, McKendrick, \& Banks, 2008). Findings from this study showed that those with a history of sexual or physical abuse were about twice as likely to report eating disorder symptoms than those without a history of abuse.

A history of physical and/or sexual abuse is common among women with SUDs (Ouimette, Kimerling, Shaw, \& Moos, 2000). The current study found that consistent with past literature (Briere \& Scott, 2007; Gustafson \& Sarwer, 2004) women with a history of abuse were more likely to screen positive for eating disorders and reported higher levels of eating disorder symptoms compared to those with no past history of abuse. The commonality of past trauma as a risk factor for eating disorders in substance users is consistent with theoretical links proposed in the 'self-medication' hypothesis (Khantzian, 1997). That is, substances and food may both function to attenuate the negative feeling and memories from abuse. Correspondingly, clinicians need to be aware that past trauma in women with SUD can increase the risk of comorbid eating disorders symptoms.

Women with higher severity of symptoms of depression and anxiety had greater odds of eating disorder symptoms, a positive eating disorder screen and/or a history of eating disorder. The link between SUD and poor mental health is well established (Teeson et al., 2014) and the results of this study provide evidence that mental health problems should ideally be addressed in treatment. Furthermore, identifying women with eating disorder symptoms allows a potentially more vulnerable group of clients to receive the additional services they are likely to require.

Another important finding was that about $15 \%$ of women reported secrecy around their eating, and that those with a past sexual and/or physical abuse were nearly two-times more likely to report secrecy. This is not surprising as secrecy along with social withdrawal is common among individuals misusing substances as well as those who experience eating disorder symptoms (Ahern, Stuber, \& Galea, 2007; Luoma et al., 2013). Secrecy can contribute to poor psychosocial outcomes for substance dependence and eating disorder symptoms (Ahern et al., 2007; Luoma, 
O’Hair, Kohlenberg, Hayes, \& Fletcher, 2010). Rates of hospitalisation and medical treatment are higher in the substance use population than other populations (NSW Health, 2015; Perron et al., 2011). Findings show that these rates are elevated in women who also experience eating disorder symptoms. This highlights the vulnerability of this sub-group of women in the SUD population. It also demonstrates the additional burden placed on the health system when such comorbidity is present.

Past researchers have highlighted the preference of individuals to engage in mental health treatment concurrently with AOD treatment, as well as the effectiveness of integrated approaches for CODs (Baker et al., 2010; Drake, Mueser, Brunette, \& McHugo, 2004; Vella et al., 2015). In a study that included an intervention (Healthy Steps to Freedom) for eating disorder amongst women in treatment for substance use disorders, it was found that there were significant increases in health-related behaviours and knowledge, and decreased body dissatisfaction and eating disorder symptoms (Lindsay, Warren, Velasquez, \& Lu, 2012).

Even though there is a growing body of evidence for integrated mental health treatment and the effectiveness of specific interventions to address eating disorders, there remains a need to improve service provision to meet the needs of individuals with such co-morbidity (Vella et al., 2015). Many treatment centres in Australia (Kavanagh \& Connolly, 2009) and overseas are not well equipped to provide concurrent treatment for CODs, including eating disorders (Vella et al., 2015).

There are limitations to this study, which need to be considered. Firstly, more detailed measures of eating disorders would be helpful. The ESP items used in this study gave an indication of eating disorder symptoms, but the validity of these items has not been tested in a psychiatric or substance use sample. The use of more comprehensive measures for assessing eating disorders is required (e.g., Eating Disorders Examination; Meadows, Palmer, Newball, \& Kenrick, 1986). Future studies should consider including information on body weight or body mass index (BMI) as this additional information helps to ascertain whether weight concerns are consistent with eating disorder symptoms secondary to SUD or a pre-existing condition that has become worse during treatment and recovery (Killeen et al., 2015). The average age of onset of eating disorder behaviours would be useful to include in further research. Finally, future research should use a longitudinal design to understand the directionality of associations better, and to understand the chronology of the co-morbid disorders. 
The findings of the present study suggest that eating disorder symptoms are common among females in substance use treatment centres. In addition, a history of physical and/or sexual abuse appeared to be related to eating disorders symptoms. The results indicate that it is vital to recognise, address and treat eating disorders alongside drug and alcohol abuse treatment, even though this presents great challenges as both substance use disorders and eating disorders are difficult to treat, long-term and lifethreatening (Vastag, 2001). There is a clear need for increasing awareness and research on eating disorder symptoms among women in treatment for substance use issues due to the prevalence, associated risk, and the influences it has on conceptualisation, treatment plans and relapse prevention (Cohen et al., 2010). Future studies should explore integrated treatment approaches to optimise long-term health and recovery.

\section{ACKNOWLEDGEMENTS}

NIL

\section{DISCLOSURES}

The authors have no conflict of interest to declare

\section{FUNDING}

A/Prof Kelly holds research consultancies with The Salvation Army and conducts ongoing collaborative research with The Salvation Army. Prof Deane has previously held research grant consultancies provided by The Salvation Army.

\section{References}


Ahern, J., Stuber, J., \& Galea, S. (2007). Stigma, discrimination, and the health of illicit drug users. Drug and Alcohol Dependence, 88(2), 188-196. doi.org/10.1016/j.drugalcdep.2006.10.014

Anstine, D., \& Grinenko, D. (2000). Rapid screening for disordered eating in collegeaged females in the primary care setting. J Adolesc Health, 26(5), 338-342.

Baker, A. L., Kavanagh, D. J., Kay-Lambkin, F. J., Hunt, S. A., Lewin, T. J., Carr, V. J., \& Connolly, J. (2010). Randomized controlled trial of cognitivebehavioural therapy for coexisting depression and alcohol problems: shortterm outcome. Addiction, 105(1), 87-99. doi:10.1111/j.13600443.2009.02757.x

Bodin, M. C., \& Romelsjö, A. (2006). Predictors of abstinence and nonproblem drinking after 12-step treatment in Sweden. Journal of studies on alcohol, 67(1), 139-146.

Bonfa, F., Cabrini, S., Avanzi, M., Bettinardi, R., Spotti, R., \& Uber, E. (2008). Treatment dropout in drug-addicted women: Are eating disorders implicated? Eating and Weight Disorders, 13(2), 81-86.

Brecht, M. L., O’Brien, A., von Mayrhauser, C., \& Anglin, M. D. (2004). Methamphetamine use behaviors and gender differences. Addictive Behavior. Addictive Behavior, 29, 89-106.

Brewerton, T. D. (2011). Posttraumatic stress disorder and disordered eating: food addiction as self-medication. $J$ Women's Health, 20(8), 1133-1134. doi:10.1089/jwh.2011.3050.

Briere, J., \& Scott, C. (2007). Assessment of trauma symptoms in eating-disordered populations. Eat Disord, 15(4), 347-358. doi:10.1080/10640260701454360

Bulik, C. M., Klump, K. L., Thornton, L., Kaplan, A. S., Devlin, B., Fichter, M. M., ... \& Mitchell, J. E. (2004). Alcohol use disorder comorbidity in eating disorders: a multicenter study. The Journal of clinical psychiatry.

Calero-Elvira, A., Krug, I., Davis, K., Lopez, C., Fernandez-Aranda, F., \& Treasure, J. (2009). Meta-analysis on drugs in people with eating disorders. Eur Eat Disord Rev, 17(4), 243-259. doi:10.1002/erv.936

Carroll, J. F., \& McGinley, J. J. (2001). A screening form for identifying mental health problems in alcohol/other drug dependent persons. Alcoholism Treatment Quarterly, 19(4), 33-47.

CASA. (2003). Food for Thought: Substance Abuse and Eating Disroders. Retrieved from Columbia University: http://www.casacolumbia.org/templates/Publications_Reports.aspx

Cohen, L. R., Greenfield, S. F., Gordon, S., Killeen, T., Jiang, H., Zhang, Y., \& Hien, D. (2010). Survey of eating disorder symptoms among women in treatment for substance abuse. Am J Addict, 19(3), 245-251. doi:10.1111/j.15210391.2010.00038.x

Corp, I. (2016). IBM SPSS Statistics for Macintosh, Version 25.0. Retrieved from Armonk, NY:

Corstorphine, E., Waller, G., Lawson, R., \& Ganis, C. (2007). Trauma and multiimpulsivity in the eating disorders. Eating Behaviors, 8(1), 23-30. doi:https://doi.org/10.1016/j.eatbeh.2004.08.009

Cotton, M., Ball, C., \& Robinson, P. (2003). Four simple questions can help screen for eating disorders. J Gen Intern Med, 18(1), 53-56.

Davidson, L., \& White, W. (2007). The concept of recovery as an organising principle for integrating mental health and addiction services. The Journal of Behavioural Health Services \& Research, 24(2), 109-120. 
Dawe, S., \& Loxton, N. J. (2004). The role impulsivity in the development of substance use disorders and eating disorders. Neuroscience and Biobehavioural Reviews, 28, 343-351.

Drake, R. E., Mueser, K. T., Brunette, M. F., \& McHugo, G. J. (2004). A review of treatments for people with severe mental illnesses and co-occurring substance use disorders. Psychiatric Rehabilitation Journal, 27(4), 360-374.

Dworkin, E. R. (2018). Risk for Mental Disorders Associated With Sexual Assault: A Meta-Analysis. Trauma, Violence, \& Abuse, O(0). doi: $10.1177 / 1524838018813198$

Dworkin, E. R., Menon, S. V., Bystrynski, J., \& Allen, N. E. (2017). Sexual assault victimization and psychopathology: A review and meta-analysis. Clin Psychol Rev, 56, 65-81. doi:10.1016/j.cpr.2017.06.002

Franko, D. L., Dorer, D. J., Keel, P. K., Jackson, S., Manzo, M. P., \& Herzog, D. B. (2005). How do eating disorders and alcohol use disorder influence each other? Int J Eat Disord, 38(3), 200-207. doi:10.1002/eat.20178

Freund, K. M., Graham, S. M., Lesky, L. G., \& Moskowitz, M. A. (1993). Detection of bulimia in a primary care setting. J Gen Intern Med, 8(5), 236-242.

Gadalla, T., \& Piran, N. (2007). Co-occurrence of eating disorders and alcohol use disorders in women: a meta-analysis. Arch Womens Ment Health, 10(4), 133140. doi:10.1007/s00737-007-0184-x

Gilchrist, G., Gruer, L., \& Atkinson, J. (2007). Predictors of neurotic symptom severity among female drug users in Glasgow, Scotland. Drugs: education, prevention and policy, 14(4), 347-365.

Gustafson, T. B., \& Sarwer, D. B. (2004). Childhood sexual abuse and obesity. Obesity Reviews, 5(3), 129-135.

Harrop, E. N., \& Marlatt, G. A. (2010). The comorbidity of substance use disorders and eating disorders in women: prevalence, etiology, and treatment. Addict Behav, 35(5), 392-398. doi:10.1016/j.addbeh.2009.12.016

Heiland, T. L., Murray, D. S., \& Edley, P. P. (2008). Body image of dancers in Los Angeles: the cult of slenderness and media influence among dance students. Research in Dance Education, 9(3), 257-275.

Hien, D., Cohen, L. R., \& Campbell, A. (2005). Is traumatic stress a vulnerability factor for women with substance use disorders? Clinical Psychology Review, 25(6), 813-823.

Holzer, S. R., Uppala, S., Wonderlich, S. A., Crosby, R. D., \& Simonich, H. (2008). Mediational significance of PTSD in the relationship of sexual trauma and eating disorders. Child Abuse \& Neglect, 32(5), 561-566.

Hu, L., Matthews, A., Shmueli-Blumberg, D., Killeen, T. K., Tai, B., \& VanVeldhuisen, P. (2018). Prevalence of obesity for opioid- and stimulantdependent participants in substance use treatment clinical trials. Drug and Alcohol Dependence, 190, 255-262. doi.org/10.1016/j.drugalcdep.2018.06.014

Kavanagh, D. J., \& Connolly, J. M. (2009). Interventions for co-occurring addictive and other mental disorders (AMDs). Addictive Behaviors, 34(10), 838-845.

Kaysen, D., Atkins, D. C., Moore, S. A., Lindgren, K. P., Dillworth, T., \& Simpson, T. (2011). Alcohol use, problems, and the course of posttraumatic stress disorder: A prospective study of female crime victims. Journal of Dual Diagnosis, 7(4), 262-279.

Kaysen, D., Simpson, T., Dillworth, T., Larimer, M. E., Gutner, C., \& Resick, P. A. (2006). Alcohol problems and posttraumatic stress disorder in female crime 
victims. Journal of Traumatic Stress: Official Publication of The International Society for Traumatic Stress Studies, 19(3), 399-403.

Khantzian, E. J. (1997). The self-medication hypothesis of substance use disorders: a reconsideration and recent applications. Harv Rev Psychiatry, 4(5), 231-244. doi.org/10.3109/10673229709030550

Killeen, T., Brewerton, T. D., Campbell, A., Cohen, L. R., \& Hien, D. A. (2015). Exploring the relationship between eating disorder symptoms and substance use severity in women with comorbid PTSD and substance use disorders. Am J Drug Alcohol Abuse, 41(6), 547-552. doi:10.3109/00952990.2015.1080263

Lindsay, A. R., Warren, C. S., Velasquez, S. C., \& Lu, M. (2012). A gender-specific approach to improving substance abuse treatment for women: The Healthy Steps to Freedom program. J Subst Abuse Treat, 43(1), 61-69. doi:10.1016/j.jsat.2011.10.027

Lovibond, P. F., \& Lovibond, S. H. (1995). The structure of negative emotional states: Comparison of the Depression Anxiety Stress Scales (DASS) with the Beck Depression and Anxiety Inventories. Behaviour research and therapy, 33(3), 335-343.

Luoma, J. B., Nobles, R. H., Drake, C. E., Hayes, S. C., O'Hair, A., Fletcher, L., \& Kohlenberg, B. S. (2013). Self-Stigma in Substance Abuse: Development of a New Measure. J Psychopathol Behav Assess, 35(2), 223-234. doi:10.1007/s10862-012-9323-4

Luoma, J. B., O’Hair, A. K., Kohlenberg, B. S., Hayes, S. C., \& Fletcher, L. (2010). The development and psychometric properties of a new measure of perceived stigma toward substance users. Substance Use \& Misuse, 41(1-2), 47- 57.

McLellan, A. T., Kushner, H., Metzger, D., Metzger, D., Peters, R., Smith, I., . . . Argerious, M. (1992). The fifth edition of the Addiction Severity Index. $J$ Subst Abuse Treat, 9(3), 199-213.

Meadows, G. N., Palmer, R. L., Newball, E. U. M., \& Kenrick, J. M. T. (1986). Eating attitudes and disorder in young women: a general practice based survey. Psychological Medicine, 16(2), 351-357. doi:10.1017/S003329170000917X

Mole, T. B., Irvine, M. A., Worbe, Y., Collins, P., Mitchell, S. P., Bolton, S., . . . Voon, V. (2015). Impulsivity in disorders of food and drug misuse. Psychological Medicine, 45(4), 771-782.

NSW Health. (2015). The Hospital Drug amnd Alcohol Consultation Liaison: Model of Care. North Sydney, NSW: NSW Ministry of Health Retrieved from health.nsw.gov.au.

Ouimette, P. C., Kimerling, R., Shaw, J., \& Moos, R. H. (2000). Physical and Sexual Abuse Among Women and Men with Substance Use Disorders. Alcoholism Treatment Quarterly, 18(3), 7-17. doi:10.1300/J020v18n03_02

Perron, B. E., Bohnert, A. S., Monsell, S. E., Vaughn, M. G., Epperson, M., \& Howard, M. O. (2011). Patterns and correlates of drug-related ED visits: results from a national survey. Am J Emerg Med, 29(7), 704-710. doi.org/10.1016\%2Fj.ajem.2010.01.044

Rayworth, B. B., Wise, L. A., \& Harlow, B. L. (2004). Childhood abuse and risk of eating disorders in women. Epidemiology, 15(3), 271-278.

Roberts, N. P., Roberts, P. A., Jones, N., \& Bisson, J. I. (2015). Psychological interventions for post-traumatic stress disorder and comorbid substance use disorder: A systematic review and meta-analysis. Clinical Psychology Review, $38,25-38$. 
Sacks, J. Y., McKendrick, K., \& Banks, S. (2008). The impact of early trauma and abuse on residential substance abuse treatment outcomes for women. Journal of Substance Abuse Treatment, 34(1), 90-100. doi.org/10.1016/j.jsat.2007.01.010

Schäfer, I., Gromus, L., Atabaki, A., Pawils, S., Verthein, U., Reimer, J., . . Martens, M. (2014). Are experiences of sexual violence related to special needs in patients with substance use disorders? A study in opioid-dependent patients. Addictive Behaviors, 39(12), 1691-1694. doi.org/10.1016/j.addbeh.2014.07.008

Schäfer, I., Verthein, U., Oechsler, H., Deneke, C., Riedel-Heller, S., \& Martens, M. (2009). What are the needs of alcohol dependent patients with a history of sexual violence? A case-register study in a metropolitan region. Drug and Alcohol Dependence, 105(1), 118-125. doi.org/10.1016/j.drugalcdep.2009.06.020

Schoemaker, C., Smit, F., Bijl, R. V., \& Vollebergh, W. A. (2002). Bulimia nervosa following psychological and multiple child abuse: Support for the selfmedication hypothesis in a population-based cohort study. International Journal of Eating Disorders, 32(4), 381-388.

Schulte, E. M., Grilo, C. M., \& Gearhardt, A. N. (2016). Shared and unique mechanisms underlying binge eating disorder and addictive disorders. Clin Psychol Rev, 44, 125-139. doi:10.1016/j.cpr.2016.02.001

Simpson, T. L., Stappenbeck, C. A., Luterek, J. A., Lehavot, K., \& Kaysen, D. L. (2014). Drinking motives moderate daily relationships between PTSD symptoms and alcohol use. Journal of Abnormal Psychology, 123(1).

Stice, E., Marti, C. N., \& Rohde, P. (2013). Prevalence, incidence, impairment, and course of the proposed DSM-5 eating disorder diagnoses in an 8-year prospective community study of young women. J Abnorm Psychol, 122(2), 445-457. doi:10.1037/a0030679

Teeson, M., Baker, A. L., Deady, M., Mills, K., Kay-Lambkin, F. J., Haber, P., . . . Gournay, K. (2014). Mental Health and Substance Use: Opportunities for Innovative Prevention and Treatment. Retrieved from Sydney: https://nswmentalhealthcommission.com.au

Teeson, M., Slade, T., \& Mills, K. (2009). Comorbidity in Australia: Findings of the 2007 National Survey of Mental Health and Well Being. Australian and New Zealand Journal of Psychiatry, 43, 606-614.

Treuer, T., Koperdák, M., Rózsa, S., \& Füredi, J. (2005). The impact of physical and sexual abuse on body image in eating disorders. European Eating Disorders Review, 13(2), 106-111. doi:10.1002/erv.616

Ullman, S. E., Filipas, H. H., Townsend, S. M., \& Starzynksi, L. L. (2005). Trauma exposure, posttraumatic stress disorder and problem drinking in sexual assault survivors. Journal of studies on alcohol and drugs, 66(5), 610-619.

Ullman, S. E., Relyea, M., Peter-Hagene, L., \& Vasquez, A. L. (2013). Trauma histories, substance use coping, PTSD, and problem substance use among sexual assault victims. Addictive Behaviours, 38(6), 2219-2223.

Vastag, B. (2001). What's the connection? No easy answer for people with eating disorders and drug abuse. JAMA, 285(8), 1006-1007.

Vella, V. E., Deane, F. P., \& Kelly, P. J. (2015). Comorbidity in detoxification: symptom interaction and treatment intentions. J Subst Abuse Treat, 49, 35-42. doi:10.1016/j.jsat.2014.07.016 
Warren, C. S., Lindsay, A. R., White, E. K., Claudat, K., \& Velasquez, S. C. (2013). Weight-related concerns related to drug use for women in substance abuse treatment: prevalence and relationships with eating pathology. J Subst Abuse Treat, 44(5), 494-501. doi:10.1016/j.jsat.2012.08.222 
Table 1. Sample sociodemographic and clinical characteristics $(\mathrm{N}=1444)$

\begin{tabular}{lll}
\hline & $\mathbf{n}$ & $\mathbf{\%}$ \\
\hline Indigenous and/or Torres Strait Islander & 38 & 10.7 \\
Yes & 276 & 78.0 \\
No & 40 & 11.3 \\
Other & & \\
Education & 1168 & 81.2 \\
Up to high school & 122 & 8.5 \\
Post secondary & 148 & 10.3 \\
Tertiary & & \\
Employment & 575 & 40.7 \\
Working (full-time, part-time or casual) & 468 & 33.1 \\
Unemployed & 73 & 5.2 \\
Retired/disability & 242 & 17.1 \\
Homemaker & 55 & 3.9 \\
Other & & \\
Marital status & 98 & 7.0 \\
Married & 467 & 33.5 \\
Separated/divorced/widowed & 829 & 59.5 \\
Never married & & \\
Primary drug of concern & 770 & 53.3 \\
Alcohol & 253 & 17.5 \\
Amphetamines & 144 & 10.0 \\
Cannabis & 277 & 19.2 \\
Other & & \\
\hline
\end{tabular}

Was there ever a period in your life when you spent a lot of time thinking and worrying about gaining weight, becoming fat, or controlling your eating? For example, by repeatedly dieting or fasting, engaging in much exercise to compensate for binge eating.

Yes

Eating disorder screen

Negative

Positive

Are you satisfied with your eating patterns?

No

Do you ever eat in secret?

Yes

Does your weight affect the way you feel about yourself?

Yes

Do you currently suffer with or have you ever suffered in the past
644

579

857

376

215

889
47.0

40.3

59.7

26.0

14.9

61.8

Yes 
Table 2. Logistic regression results for predictors of the eating disorder screen and the MHSF-III (Eating disorders)

\begin{tabular}{lllll}
\hline & ESP & & \multicolumn{2}{l}{$\begin{array}{l}\text { MHSF-III } \\
\text { (Eating disorders) }\end{array}$} \\
& $B(S E)$ & Odds Ratio & $B(S E)$ & Odds Ratio \\
\hline Sexual abuse & $.67(.12)$ & $1.96^{* * *}$ & $.66(.13)$ & $1.93^{* * *}$ \\
Physical abuse & $.47(.14)$ & $1.59^{* * *}$ & $.66(.12)$ & $1.93^{* * *}$ \\
Primary substance of use is alcohol & $.02(.13)$ & 1.02 & $.40(.13)$ & $1.49^{* *}$ \\
DASS Total & $.01(.00)$ & $1.01^{* *}$ & $.01(.00)$ & $1.01^{*}$ \\
\hline
\end{tabular}

${ }^{*} p<.05, * * p<.01, * * p<.001$.

Note. The ESP is the Eating Disorder Screen for Primary Care. DASS is the Depression, Anxiety, Stress Scale-21.

The eating disorders item of the MHSF-III is "Was there ever a period in your life when you spent a lot of time thinking and worrying about gaining weight, becoming fat, or controlling your eating? For example, by repeatedly dieting or fasting, engaging in much exercise to compensate for binge eating. Binomial regression adjusted for age

Table 3. Logistic regression results for predictors of the four screening items of the eating disorder screen

\begin{tabular}{|c|c|c|c|c|c|c|c|c|}
\hline & \multicolumn{2}{|c|}{ Satisfied } & \multicolumn{2}{|l|}{ Secret } & \multicolumn{2}{|c|}{ Weight } & \multicolumn{2}{|c|}{ Past/current ED } \\
\hline & $B(S E)$ & $\begin{array}{l}\text { Odd } \\
\text { ratio }\end{array}$ & $B(S E)$ & $\begin{array}{l}\text { Odds } \\
\text { Ratio }\end{array}$ & $B(S E)$ & $\begin{array}{l}\text { Odds } \\
\text { Ratio }\end{array}$ & $B(S E)$ & $\begin{array}{l}\text { Odds } \\
\text { Ratio }\end{array}$ \\
\hline $\begin{array}{l}\text { Sexual } \\
\text { abuse }\end{array}$ & $\begin{array}{l}-.30 \\
(.14)\end{array}$ & $.74^{*}$ & $\begin{array}{l}.57 \\
(.18)\end{array}$ & $1.77 * * *$ & $\begin{array}{l}.54 \\
(.12)\end{array}$ & $1.71 * * *$ & $\begin{array}{l}.54 \\
(.13)\end{array}$ & $1.72 * * *$ \\
\hline $\begin{array}{l}\text { Physical } \\
\text { abuse }\end{array}$ & $\begin{array}{l}-.50 \\
(.14)\end{array}$ & $.61 * * *$ & $\begin{array}{l}.56 \\
(.19)\end{array}$ & $1.75 * *$ & $\begin{array}{l}.37 \\
(.12)\end{array}$ & $1.44 * * *$ & $\begin{array}{l}.74 \\
(.16)\end{array}$ & $2.10 * * *$ \\
\hline $\begin{array}{l}\text { Primary } \\
\text { substance of } \\
\text { use is } \\
\text { alcohol }\end{array}$ & $\begin{array}{l}.14 \\
(.14)\end{array}$ & 1.14 & $\begin{array}{l}.06 \\
(.18)\end{array}$ & 1.06 & $\begin{array}{l}.01 \\
(.13)\end{array}$ & 1.10 & $\begin{array}{l}.31 \\
(.14)\end{array}$ & $1.36^{* * *}$ \\
\hline DASS Total & $\begin{array}{l}.00 \\
(.00)\end{array}$ & .99 & $\begin{array}{l}.01 \\
(.00)\end{array}$ & $1.01 *$ & $\begin{array}{l}.01 \\
(.00)\end{array}$ & $1.01 * *$ & $\begin{array}{l}.01 \\
(.00)\end{array}$ & $1.01 * *$ \\
\hline
\end{tabular}

$* p<.05, * * p<.01, * * p<.001$

Note. 'Satisfied' is "Are you satisfied with your eating patterns?"; 'Secret' is "Do you ever eat in secret?", 'Weight' is "Does your weight affect the way you feel about yourself?"; and 'Past/current ED' is "Do you currently suffer with or have you ever suffered in the past with an eating disorder?". Binomial regression adjusted for age. DASS is the Depression, Anxiety, Stress Scale-21. ED is Eating Disorder. 